\title{
Correction to: COVID-19 and people who use drugs: a call for action
}

\section{Ehsan Jozaghi ${ }^{1,2} \cdot$ Russ Maynard ${ }^{3} \cdot$ Dave Hamm $^{4}$ - Samona Marsh ${ }^{5,6,7,8}$}

Published online: 12 June 2020

(C) The Canadian Public Health Association 2020

\section{Correction to: Canadian Journal of Public Health https://doi.org/10.17269/s41997-020-00326-1}

This article was updated to correct the spelling of Dave Hamm's name: it is correct as displayed here.

Publisher's note Springer Nature remains neutral with regard to jurisdictional claims in published maps and institutional affiliations.

The online version of the original article can be found at https://doi.org/ 10.17269/s41997-020-00326-1

Ehsan Jozaghi

ejozaghi@yahoo.com

1 The British Columbia Centre for Disease Control, 655 W 12th Ave, Vancouver, BC V5Z 4R4, Canada

2 School of Population and Public Health, University of British Columbia, 2206 East Mall, Vancouver, BC V6T 1Z3, Canada

3 PHS Community Services Society, 9 E Hastings St, Vancouver, BC V6A 1M9, Canada
4 Vancouver Area Network of Drug Users, 380 E Hastings St, Vancouver, BC V6A 1P4, Canada

5 Western Aboriginal Harm Reduction Society, 380 E Hastings St, Vancouver, BC V6A 1P4, Canada

6 The BC-Yukon Association of Drug War Survivors, 380 E Hastings, St, Vancouver, BC V6A 1P4, Canada

7 Sex Workers United Against Violence, 334 Alexander St, Vancouver, BC V6A 1C3, Canada

8 Canadian Association of People Who Use Drugs, Vancouver, BC, Canada 